\title{
Importance of Nonviolent Communication in Intercultural Dialogue
}

\author{
Sayantani Roy \\ Assistant Professor, Amity School of Communication, Amity University, Madhya Pradesh, India \\ Corresponding author: srsayantaniroy@gmail.com
}

Received: 06 Frb., 2019

Revised: 09 Apr., 2019

Accepted: 23 May, 2019

\begin{abstract}
In a globalized world, where there is global interdependence and consciousness, highlighting the virtues of particularism, are bound to produce new cultural conflicts. In such conflicts, religious traditions play a special role, since they can be mobilized to provide an ultimate justification for one's view of the globe. Closely linked to the process of globalization is therefore the problem of interaction between cultural or religious actors and communities holding different views of world order. Therefore, while the very idea of a clash of civilizations is wrong, a civilization of clashes is today's reality. That is what makes intercultural dialogue among cultures and peoples an urgent matter of national and international affairs. Therefore it is pertinent to understand whether in today's world cultures should, could and would engage in an intercultural dialogue with each other therefore this article will explore the importance of nonviolent communication in the arena of intercultural dialogue and the various strategies for utilizing nonviolent communication for effecting intercultural dialogue utilizing Mahatma Gandhi's Theory of Nonviolent Communication. This paper aims to establish how by imbibing nonviolent communication as a habit to reach out to people even opponents, people can take the lead globally to contribute towards a culture of peace and nonviolence with intercultural dialogue.
\end{abstract}

Keywords: Intercultural Dialogue, Nonviolent Communication, Culture of peace, mindfulness

With the globalization process, the world has been offering a numerous of opportunities to the world at large. Opportunities to meet with each other, to travel, exchange ideas, discover other cultures and backgrounds enrich from the differences. All of this undoubtedly raises new questions. Questions about the meaning of 'progress' about the foundations for peace and sustainability, for inter-culturalism and respect for human rights and fundamental freedoms and protection of environment and climate change.

The Nobel Peace Prize laureate Adolfo Perez Esquivel (2015) stresses on the idea that new generations should 'understand, engage and fight to build a different society, one in which peace is the foundation of life on a personal, social, political, economic and spiritual level and in which atrocities such as Hiroshima and Nagasaki bombings, concentration camps and wars are never again repeated."

Esquivel further notes, "True hope for the future consists of shaping young minds capable of making a difference." He says, "War is born in the minds of men, and if we are to find new paths toward the resolution of conflicts, we must disarm the armed conscience." Esquivel's argument on the need to shape young minds to find new paths towards resolution of conflicts takes us to different approaches youth can take to contribute to peace building.

In this context Borkova (2017) remarked "sustainability, the promotion of cultural diversity, 
of intercultural dialogue, are not a matter for governments alone, but for all segments of society, including universities, civil society and the private sector." He further pointed out "we must indeed strengthen the values we share and recognize the destiny we hold in common. This is not a 'clash of civilizations'. This is a clash between those who do not believe that we can live together, and those who believe that we can. We need stronger media literacy and freedom of expression, to ensure every woman and man can reject messages of hatred. We need a new focus on young people, on education for peace, for global citizenship, because young women and men are architects for the future we want for all. This is why safeguarding culture is far more than a cultural issue today - this is about peace-building. Cultural diversity and intercultural dialogue are not a threat. They are an asset".

Borkova's idea put forward the importance of intercultural dialogue among cultures and peoples an urgent matter of national as well as international affairs. But that dialogue has to be meaningful in a spirit of reciprocity, mutual recognition, solidarity and it has to be inculcated with cultural broad-mindedness. Intercultural dialogue can be inspired by several considerations and in each case it takes the form of a hermeneutical quest for inter-civilizational reflection on the modes of global existence. This intercultural dialogue might be intended to foster mutual understanding or it might be considered as a way of addressing global issues like climate change, strengthening media literacy.

Meanwhile in the backdrop of increasing new opportunities and side by side social tensions and conflicts in our societies, Ikeda (2007) suggests three principles and guidelines for communication: (1) exchange among civilizations as a source of value creation; (2) a spirit of open dialogue; and (3) the creation of a culture of peace through education. The challenge to communications today, he says, is to address the lack of true dialogue linking the hearts of one individual to another.

The spirit of open dialogue can also be found in Gandhi's ideology. His dialogue was not merely with words or ideas or theory it is springing from his love for Truth (Satya) and nonviolence (Ahimsa) which is an important guiding post for the importance of practicing nonviolent communication in intercultural dialogue. In Harijan he wrote : My writing cannot be poisonous, they must be free from anger, for it is my special religious conviction that we cannot truly attain our goal by promoting ill will... There cannot be room for untruth in my writings, because it is my unshakable belief that there is no religion other than truth. My writings cannot but be free from hatred towards any individual because it is my firm belief that it is love that sustains earth.

So it is pertinent to understand whether in today's world cultures should, could and would engage in an intercultural dialogue with each other therefore this article will explore the importance of nonviolent communication in the arena of intercultural dialogue and the various strategies for utilizing nonviolent communication for effecting intercultural dialogue utilizing Mahatma Gandhi's Theory of Nonviolent Communication.

\section{Towards Understanding Intercultural Dialogue}

Bennett (1998) states that intercultural communication- that is, communication between people of different cultures, cannot allow a simple assumption of similarities. Their languages, behaviour patterns, and values of the different cultures have different features. Intercultural communication is a difference-based approach.

UNESCO Survey on Intercultural Dialogue 2017 points out (a) Context is crucial to defining and applying intercultural dialogue. (b) Intercultural dialogue is a necessary environment for social cohesion and peace, and is instrumental in achieving related goals. (c) Intercultural dialogue is increasingly recognized for its contribution to maintaining peaceful societies and preventing conflict. (d) Intercultural dialogue is a wide-ranging concept and multi-stakeholder engagement is key to ensuring its implementation. (e) Economic development is regarded as the least pertinent factor contributing to and resulting from intercultural dialogue. 
The Council of Europe has proposed the most widely cited definition of Intercultural Dialogue "Intercultural dialogue is a process that comprises an open and respectful exchange or interaction between individuals, groups and organizations with different cultural backgrounds or world views. Among its aims are: to develop a deeper understanding of diverse perspectives and practices; to increase participation and the freedom and ability to make choices; to foster equality; and to enhance creative processes".

It further noted "Dialogue is at the heart of the concept of intercultural dialogue, the goal of which is the creation of understanding among the interacting parties and not necessarily the resolution of differences via a rationalistic deductive reasoning. Via a process of listening and the respectful exchange of views, this dialogue seeks to engage participants in 'a deeper understanding of diverse world views and practices, to increase co-operation and participation (or the freedom to make choices), to allow personal growth and transformation, and to promote tolerance and respect for the other." This definition situates intercultural dialogue beyond mere tolerance of the other and also situates deep shared understandings, as well as new forms of creative and expressive communication as dialogic outcomes.

Intercultural learning is learning from other cultures (Baraldi, 2006). Dialogue is a good way of expressing oneself to another person. Dialogue is more efficient in creating empathy and participation in communication. Empathy implies perceiving the interests and the needs of others. Participation conveys sharing cultural exchanges. Intercultural learning is learning from other cultures; other words and other forms emerge and are used. Dialogue consists of understanding, listening, and sharing, of experiences and interests. (Baraldi, 2006).

On the importance of intercultural dialogue Amartya Sen uttered (2005) the spirit of dialogue and admissibility of heterodoxy matches the respect for plurality in Indian traditions.

Upadhyay (2017) further articulated that the acceptance of diversity and dialogue has been a constant feature of Indian civilization. There are countless references to diversity and plural visions in leading ancient Indian (Sanskrit) texts such as the Vedas and Upanishads. The Rig Veda, one of the most coveted texts of Hindu philosophy, thus declared 'Ekam sad vipra bahudha vadanti' (truth is one; sages call it by various names) and 'Aano bhadra krtavo yantu vishvatah' (may noble and auspicious thoughts come to us from all over). He further added The spirit of pluralism and dialogue has found expression in all phases of Indian history ranging from the rock edicts of King Ashoka (circa 270 BC) to the Moghul Emperor Akbar (circa 1580 AD), who frequently organized dialogues between the Sunni Ulemmas, Sufi Shaikhs, Hindu Pundits, Parsis, Zoroastrians, Jains and Catholics in search of shared values and practices. At the level of the common masses, multicultural rituals and practices facilitated a peaceful transaction of intercommunity with demotic, superstitious and local practices. This tradition of dialogue continued in the twentieth century with spiritual leaders like Ramakrishna Paramahamsa, Ramana Maharshi, Nisargadatta Maharaj and J Krishnamurti constantly engaged in dialogues with their own disciples and others.

On the importance of intercultural dialogue Jiddu Krisnamurti ${ }^{1}$ remarked: A dialogue is very important. It is a form of communication in which question and answer continue till a question is left without an answer. Thus the question is suspended between the two persons involved in this answer and question. It is like a bud with untouched blossoms ... If the question is left totally untouched by thought, it then has its own answer because the questioner and answerer, as persons, have disappeared. This is a form of dialogue in which investigation reaches a certain point of intensity and depth, which then has a quality that thought can never reach.

Thus the approaches of nonviolent communication like empathy, spirit of open dialogue, openness, flexibility, and maintenance of relationships and deep understanding of each other's culture are important ingredients which could contribute element in intercultural dialogue.

${ }^{1}$ Krisnamurty, Jiddu https://www.goodreads.com/quotes/256395-a-dialogueis-very-important-it-is-a-form-of. 


\section{Essence of Nonviolent Communication}

While there can be excess of efforts that can contribute to fill the gap of happiness inequality and address the challenges of rising tensions and negative emotions, internalization and practice of nonviolent communication is a powerful tool to strengthen intercultural dialogue. It can help citizens to manage anger, promote positive emotions and effectively counter the problems arising out of rising tensions. The important ingredients of nonviolent communication are: nonviolence in both our verbal and nonverbal communication; learning the power of gratitude; importance of self-awareness; avoidance of evaluative language; avoidance of stereotypes; learning the art of anger management and patience; empathetic listening; believing in the divinity of all human beings; caring for the needs of others; practicing flexibility and openness in all our communication efforts.

According to Bode for Gandhi, the goal of communication was to build and maintain human relationships and thus enhance personhood. Gandhi's insistence on nonviolence recognized the importance of others, valued humanity and appreciated the importance of human relationships and personhood...Gandhi's nonviolent communication theory included the valuing of personhood throughout the world, but he also stressed the importance of individual relationships and friendships... Openness was manifested in Gandhi's rhetoric and is a characteristics of his nonviolent communication theory.

Marshall Rosenberg (2015) using Gandhian approach to nonviolence explains nonviolent communication is a combination of thinking and language, as well as a means of using power designed to serve a specific intention. This intention is to create the quality of connection with other people and oneself that allows compassionate giving to take place. In this sense it is a spiritual practice: All actions are taken for the sole purpose of willingly contributing to the well-being of others and ourselves. The primary purpose of Nonviolent Communication is to connect with other people in a way that enables giving to take place: compassionate giving. It's compassionate in that our giving comes willingly from the heart.

He further says Nonviolent Communication helps us to connect with each other and ourselves in a way that allows our natural compassion to flourish. It guides us to reframe the way we express ourselves and listen to others by focusing our consciousness on four areas: what we are observing, feeling and needing and what we are requesting to enrich our lives. Nonviolent communication fosters deep listening, respect and empathy and engenders a mutual desire to give from the heart. Some people use nonviolent communication to respond compassionately to themselves, some to create greater depth in their personal relationships and still others to build effective relationships at work or in the political arena.

Thich Nhat Hanh's (1998) guidelines on right speech explain the nature of nonviolent communication: Aware of the suffering caused by unmindful speech and the inability to listen to others, I am committed to cultivating loving speech and deep listening in order to bring joy and happiness to others and relieve others of suffering. Knowing that words can create happiness or suffering, I am determined to learn to speak truthfully, with word that inspires self confidence, joy and hope. I will not spread news that I do not know to be certain and will not criticize or condemn things of which I am not sure. I will refrain from uttering words that can cause division or discord or words that can cause the family or the community to break. I am determined to make all efforts to reconcile and resolve all conflicts, however small.

\section{Strategies of Nonviolent communication in intercultural dialogue}

Rosenberg(2005) talks of the benefit of using it in all aspects of our life: Nonviolent communication helps us connect with each other and ourselves in a way that allows our natural compassion to flourish. It guides us to reframe the way we express ourselves and listen to others by focusing our consciousness on four areas: what we observing, feeling and needing and what we are requesting to enrich our lives. Nonviolent communication fosters deep listening, respect and empathy and engenders a mutual desire 
to give from the heart. In this backdrop it would be pertinent to understand the various strategies of utilizing nonviolent communication in building intercultural dialogue.

\section{(a) To be patient}

One of the important parameter of intercultural dialogue is to maintain patience while communicating with others. When we start communicating with ourselves, we will develop patience and before arguing with others, we will start reflecting. We can practice nonviolent communication by observing our inner self and deeply listening to our self-talk and with communicating with others. This will help us to look for creative solutions of our feelings and needs and also how we connect with others. Practicing nonviolent communication with oneself is very important.

\section{(b) Respecting other cultures and customs by adopting appropriate behavior and language}

Using appropriate language, words and maintaining positive behavior towards other customs and cultural are the key elements of nonviolent communication. If it is applied in intercultural dialogue, the communication will be mindful. It should also be noted words may have different meanings and interpretations in different cultures. By avoiding stereotype nature individuals on the basis of their race, ethnicity, religion, gender, caste, disabilities and many other criteria can respect other cultures. We generally make our responses on the basis of the stereotypes which we construct.

\section{(c) Do not over react}

Avoiding over reaction is important for nonviolent communication. Conscious attempts need to be made to sincerely listen to others. In our daily lives, we can easily feel when the other person is listening to us with sincerity and is engaging. We can easily understand that the other person is 'present'. It gives us the space for conversation and even if there are differences of views, it keeps the door open for further engagement.

\section{(d) Learn to give feedback in a sensitive way}

We must practice to express acknowledging to whatever we have and whatever anyone does for us. This is an important ingredient of nonviolent communication and it makes us more aware. If it is incorporated during an intercultural dialogue the communication will be empathetic. Lack of empathy is roadblock to proper communication and can result in conflicts.

\section{(e) Be genuine, open and inclusive}

One of the important aspects of nonviolent communication is openness. During intercultural dialouge an open and respectful and genuine exchange of views create a cooperative and willing environment for overcoming political and social tensions. In an intercultural setting, the cultural, religious, socio-economic and political backgrounds are the so-called 'differences', while the common ground is the inner-readiness and openness to deal with these differences through genuine dialogue.

\section{(f) Learn quickly to assess people and situation through their lens}

Leaning to assess people with mutual respect is one of the parameter of nonviolent communication. Effective communication begins with mutual respect; it inspires and encourages doing the best.

\section{CONCLUSION}

Globalization has propelling the various technologies and has offer great opportunities for young people to use it for promoting peace and intercultural dialogue. The challenge however is that communication in the digital age could lack a human face. Ikeda (2011) cautions on this danger, he notes, "It is true that the development of information technology presents opportunities for people to forge new connections. However, relations formed online will have no human face if they are limited to anonymous, depersonalized exchanges. Such interactions can only be inorganic and neutral, far removed from the refreshing wonder, tangible response and satisfaction that come from the effort 
to realize face-to-face, soul-to-soul communication. It is only when immersed in words and dialogue that human beings can become truly human; one cannot mature into a complete and fullfledged human being without such experiences." By overcoming this challenge and by imbibing nonviolent communication as a habit to reach out to people even opponents, people can take the lead globally to contribute towards a culture of peace and nonviolence with intercultural dialogue.

\section{REFERENCES}

Baraldi, C. 2006. New forms of intercultural communication in a globalized world. Intercultural Communication Gazette. 68: 53-69.

Bennett, M. 1998. Basic concepts of intercultural communication: A reader. Yarmouth, MA: Intercultural Press.

Borkova, I. 2017. Forward. In Fethi Mansouri (ed) interculturalism at the crossroads: Comparative perspectives on concepts, policies and practices. UNESCO.

Bode, R.A. 1995. Mahatma Gandhi's Theory of Nonviolent Communication. Paper presented at the Annual Meeting of the Western States Communication Association.

European Commission. 2008. Intercultural dialogue: Support through EU programmes. Luxembourg. Luxembourg: Office for Official Publications of the European Communities.
Retrieved from http://bookshop.europa.eu/en/interculturaldialogue-pbNC3008551

Esquivel, Adolfo Perez. 2015. 'Cultivating a New Era for Peace'. SGI Quarterly, A Buddhist

Forum for Peace, Culture and Education. Issue: 81. Soka Gakai International.

Hanh, Thich Nhat. 1998. The Heart of the Buddha's Teaching: Transforming Suffering into Peace, Joy, and Liberation. New York: Harmony

Ikeda, Daisaku. 2011. Toward a World of Dignity for All: The Triumph of the Creative Life:

Peace Proposal 2011. Soka Gakai International.

Ikeda, Daisaku. 2007. Interaction of Civilizations Leads to a Flourishing Culture of Humanity (University of Palermo, 2007). Retrieved on $11^{\text {th }}$ Oct 2018 from https://www. daisakuikeda.org/sub/resources/works/lect/lect-11.html

Rosenberg, M.B. 2015. Nonviolent communication: A language of life. $2^{\text {nd }} \mathrm{ed}$. Encinitas: Puddle Dancer Press.

Rosenburg, M.B. 2005. Speak Peace in a world of conflict. What you say next will change your world. Encinitas: Puddle Dancer Press

Sen, A. 2005. The Argumentative Indian: Writings on Indian History, Culture and Identity. London: Penguin.

Upadhaya, P. 2017. Intercultural dialogue: lineage and practice in the Indian subcontinent. Forward. In Fethi Mansouri (ed) interculturalism at the crossroads: Comparative perspectives on concepts, policies and practices. UNESCO. 